\title{
Technical Analysis of Selected Stocks Time Series Based on Value Screening
}

\author{
Michal Tlustý1,** \\ ${ }^{1}$ Institute of Technology and Business, Faculty of Corporate Strategy, Okužní 517/10, 37001 České Budějovice, Czech Republic
}

\begin{abstract}
The paper deals with the issue of value screening and shares. For the selection of a company, value screening with specific criteria was used. From a total of 6 companies, the one with the most traded stocks was selected, namely the company Apple Inc. Subsequently, the analyses of trend and moving averages were performed for the 50-day, 100-day, and 200-day period, as well as the analysis using RSI indicators. Specific changes detected were graphically illustrated and described in detail in graphs. In the following chapter, Discussion of Results, specific indicators were explained, which emerged within the analysis of the shares, and proposals of measures for a broker were made, which recommended the trader to buy or give up the position. The objective of the paper, which consisted in the performance of value screening using specific criteria, select a suitable company, analyse its time series, and propose a specific measure, was achieved.
\end{abstract}

Keywords: technical analysis; shares; technical indicators; value screening; stock markets

\section{Introduction}

Stock market and stocks in general are currently a very topical issue, mainly due to the coronavirus pandemic. A lot of companies have suspended their activities or their operations have been $50 \%$ reduced, which decreases their value on stock markets. Such measures may be necessary given the current situation but it can represent a real problem in the long run. Small companies which do not have sufficient capital for surviving months without any income in the situation when fixed costs still need to be paid, will start to go bankrupt. This is followed by failure of other smaller and micro enterprises, which could produce and sell their product but since the large enterprise which had been buying $90 \%$ of their production had to suspend the operation, they go bankrupt as well. However, every pandemic will end one day, and this situation appears to be suitable for investors in stock markets, who might take advantage of these declines.

The time series shows the changes in the prices of a specific company stocks over time and helps see the context that might not be obvious at first glance. Such information is often presented in the form of a graph, which enables predicting the future development of the data under review and if necessary, to prepare for it in advance. Nevertheless, it should be born in mind that a $100 \%$ reliable prediction is not possible and might not correspond to the real development. In general, it can be said that the more and the higher quality data available, the more accurate the prediction will be.

The paper aims to use appropriately defined value screening to identify a specific company and analyse its time series using suitable tools. In conclusion, its development is predicted and investment recommendations are made.

\section{Literary research}

The key to each investment success as well as to the success of any project in general are input data. Without information, it is not possible to be successful in business in the long run, and this particularly applicable in the case of investing in stock markets. There are many ways to analyse and evaluate the input data [1], one of them being the socalled value screening. This consists of two basic components, screening as such and value investing [2]. Screening is a tool that enables traders to process a large volume of data they have to deal with and makes it easier for them to sort. In simple terms, screening helps shareholders to find the information in the vast amount of data they are able to process manually [3]. Screening is basically a new tool. Although there was a certain definition and theory of screening about twenty years ago, screening was not feasible in practice due to the fact that the Internet was not that widespread. This changed about ten years ago when the Internet underwent a major development and value screening has become a basic tool for the evaluation of stock market data. However, its price was very high; therefore, it was available only for very rich investors, who were able to convert the investments in the tool into benefits and screening was custom-made on their data. Currently, the Internet is at a high level practically all over the world and screening as such is available for free to all [4].

\footnotetext{
*Corresponding author: michaltlusty@email.cz
} 
No novice trader can execute the trade of the century or buy for extremely high prices immediately after entering the stock market. Any novice investor should have a reasonable capital and buy or sell extremely carefully [5]. Therefore, investors in the market can be classified into three individual groups. The first group includes the so-called "small players". These are beginner investors who do not have large capital and are not able to significantly influence the whole market. Their motto should be "Trend is your friend". The second group consists of the so-called "big players", mainly multinational companies that trade billions of dollars every day. An example of big players are e.g. the companies Goldman Sachs or JP Morgan [6]. The third group are the so-called "Brokers", whose task is to move the market and who represent intermediaries between the trader and the stock market [7].

It is important for any trader to be able to analyse trends correctly and deduce clues and indications from the results which would help them to decide whether to buy or not [8]. As mentioned above, one of the rules is "trend is your friend", which means that trend should be monitored and followed. A trader who follows market trends usually makes a profit, while a trade who bucks the trend at all costs usually loses [9]. The length and stability of trend followed by a trader also plays a role. If the market is stable over a longer period, the investor's chances of making a profit increase. In practice, it is thus important to find long-term and steadily growing trends that a trader might make profit from for many months or years and follow them to the very end [10].

Trends need to be analysed from several different perspectives. If the trend curve grows for a long time and suddenly turns downwards, the highest value the curve has achieved is referred to as "high". Conversely, if the trend decreases gradually and then it suddenly turns upwards, the lowest value is referred to as "low" [11]. The development of the trend in the graph can be divided into three different directions. The first one is the so-called growing trend which indicates that the increasing values of stocks outweigh declining stock prices in the long run; for a trade, this trend behaviour is a signal for investing [12]. The second situation is when decreasing values outweigh the growing values, making the trend decrease in the long run, which is a signal for a trader not to invest or to perform further analysis [13]. The third possible behaviour is the so-called sideway trend, which provides the information that both decreasing and increasing values are approximately at the same level and the trend thus does not show extreme differences. In such a case, it is recommended waiting for other signals, not investing or selling [14].

Stock trend can be divided from the time perspective into a long-term, medium-term, and short-term trend. Long-term trends are the most important ones for investors and play the most important role in market analysis. If long-term trend is growing, both short-term and medium-term trends tend to be growing as well, but it is not a [15]. Short-term trend represents a shorter period than a long-term trend, which means that although a short-term trend is decreasing, the overall long-term may still be growing. A short-term trend describes the behaviour of trend in the order of days or hours and is very time-sensitive. Short-term trends must also include the so-called fresh information, which may completely change its direction, although long-term and medium-term trends are still growing [16].

In general, there are two types of financial analyses available to traders. The first one is fundamental analysis, which deals with the data that can be obtained from the macro-economic environment of the company, state, etc., such as gross domestic product, unemployment rate in percentage or the current political situation in the state [17]. The second type is technical analysis, which deals mainly with trends, RSI indicators, moving averages, and other analyses [18]. The basic difference between fundamental and technical analysis is that technical analysis assumes repeats itself. In practice, this means that if long-term trend is growing, technical analysis assumes that the trend will still be growing based on the historical data [19]. This is only a simplified example and technical analysis can predict the repetition of a large number of successive events from the past. For example, if situation 1 occurred in the past and situation 2 followed, if situation 1 is occurring right now, based on the historical data, technical analysis predicts that situation 2 will follow [20].

In order to achieve the objective of the paper, three hypotheses are formulated:

1) The application of specific value screening criteria will find a maximum of 4 companies.

2) The technical analysis indicators will recommend buying or selling the position immediately after the beginning of the monitored period.

3) RSI indicators will recommend sell or buy, which will prove to be potentially correct in the next period

\section{Methodology}

Each analysis and prediction of stock time series require data in a specific form. Data suitable for the analysis of time series are available in many forms for free on internet websites. The most common and the most suitable type of data are data arranged in tables divided into six columns. In each row of a specific value of the stock, it is necessary to enter the date on which the value was measured, as well as open and close (the prices at which a stock began and ended trading), and high and low (the maximum and the minimum price). Some statistical datasets also contain the average closing price (adj close) and the volume of traded stocks (volume). These data are mostly used in a graph which shows the movement of stock prices. Graphs can be prepared for a short period (e.g. one hour) or for longer periods (e.g. ten years). Graphs can have a form of a stock chart or a line graph. The difference between a stock chart and a line graph is that stock chart 
is intended to be used for showing the course of a time series. Most commonly, it shows volume, open, high, low, and close.

Data for the purpose of the paper are obtained from the website Yahoo! Finance. The data show the time series of the last year (from 1 November 2019 to 1 November 2020). The values are presented in US dollars. First, it is necessary to choose a specific company, whose data are to be analysed. For this purpose, a basic screening of joint-stock companies on the US stock exchange is performed, which enables to narrow down the options using the pre-selected criteria to several companies, out of which the one which trades the highest volume per day is selected. A total of 6 criteria for screening are set according to the following arguments: The first criterion is market cap (market capitalization), which provides information about the overall value of a company. The specific selected value is a large company with a market capital of USD 10 billion or more (+Large [over \$10bln]). The second criterion is and its specific value vas selected so that the given companies were among the 500 most important publicly listed companies. Another criterion indicates the percentage of earnings the company pays on dividends, which means that the more it pays, the less money it has for investments. Due to the fact that a stable and growing company is sought, the selected value is up to $50 \%$. Another parameter is the sector the company operates in. For the purposes of this paper, only the technology sector is selected, since financial companies, companies operating in health care and other less interesting sector need to be excluded from the dataset. The next criterion is the average volume of trades per one day. In this case, the value of more than one million is selected in order to prevent the situation that all stocks are bought by a small group of traders and this is reflected in the price of stocks. The last parameter concerns the return on investment, where the value of $25 \%$ and higher is selected in order to ensure the company is profitable and growing.

Table 1. Screening criteria

\begin{tabular}{|l|l|l|}
\hline Criterion & Criterion value & Meaning \\
\hline Market cap & $>$ USD 10 billion $\$$ & Stable company \\
\hline Index & S\&P 500 & Important, publicly listed company \\
\hline Payout ratio & $<50 \%$ & Investment in innovations \\
\hline Sector & Technology & $\begin{array}{l}\text { Information on the company is } \\
\text { publicly available }\end{array}$ \\
\hline Average daily volume & $>1$ mil & Stability of traded stocks \\
\hline Return on investment & $>25 \%$ & Profitable and growing company \\
\hline
\end{tabular}

Source: Author based on finviz.com.

As already mentioned, there are many methods to analyse stock time series and investors should choose a method that would be suitable, meets their expectations, and that would be applicable in the market the investors are active in. For the purposes of this paper, two main indicators are selected, specifically moving averages and RSI indicators.

One of the basic methods for time series analysis is the method of simple moving average (SMA). It is an arithmetic average which changes over time. The most common time periods used in moving average are 30, 50 and 100 days. The basic principle of moving average (and difference between MA and arithmetic average) is that with each day, the analysed data are added a new value, i.e. the information from the current day and at the same time, the oldest value is removed. That is why the average is referred to as "moving". The fact that two data values change every day makes moving average a tool that includes irregular data and whose calculation is different and updated every day. The number of values always represents the number of days for which the moving average is calculated. This method can be used for any dataset which changes over time; in the case of stock markets, price values are most commonly used. Moving averages are recommended especially in the case of analysing a longer time series and trend functions are not sufficient for its analysis. Simple moving averages are calculated as follows:

$$
S M A=\frac{\left(P_{1}+P_{2}+\ldots+P_{n}\right)}{n}
$$

Where:

$S M A=$ Value of simple moving average

$P=$ stock price at a specific time (most often the closing price)

$n=$ overall number of values (mostly days)

Given that the calculation is based on the historical data, it is a lagging indicator. For this reason, there is another type of moving average, an exponential moving average (EMA), which works on the same principle as simple moving average, but the new and updated data are assigned higher weight that the older data. This does not mean that exponential moving 
averages represent a better method than simple moving average. This always depends on the preferences of investors and the type of market they operate in.

In practice, there are other strategies which combine two or three moving averages. If two moving averages, one of them is "slow" and the second one is "fast". Slow moving average includes more values that fast but for the same time period. In practice, this means that both slow MA and fast MA are calculated for the period of 30 days but slow MA describes one value per day, i.e. 30 values, while fast moving averages describes 24 values a day (one per hour), i.e. 720 values. In this case, fast MA describes the trend curve more in detail, and various crossovers of these two averages provide specific indications that help investors in making investment decisions. If there are three moving averages (fast, slow and medium), the principle is the same, but there are more trend crossovers and the indications are even more specific.

Another method used for analysing stock markets are RSI indicators. It is a universal tool that can be used for any market and any time period. The market analysis using RSI indicators are mostly based on closing prices and for the calculation, it is necessary to choose a relevant period. Periods indicate how many time periods of specific length the calculation includes. For example, if $\mathrm{P}=12$ and the calculation of RSI indicators is required on the hourly charts, the calculation shall include the values for the last twelve hours. The formula for calculating RSI indicators is as follows:

$$
R S I=100-\frac{100}{(1+R S)}
$$

Where:

$$
\begin{aligned}
& R S I=\text { value of RSI indicator } \\
& R S=\text { average profit from closing price / average loss from closing price }
\end{aligned}
$$

The formula shows that it is necessary to know the value of RS prior to calculating. If the calculation was carried out on the above example of twelve hours, it is necessary to determine how many times, in the overall period of twelve hours, the value was higher than its previous value and subsequently, the number is divided by the total number of values (twelve in this case). Next, it is necessary to determine how many times the value was lower than its previous value and this number shall be divided by twelve; afterwards, the first determined value shall be divided by the second determined value. If the number of values indicating that the closing price was higher than its previous price exceeded the number of values indicating that the closing price was lower than its previous price, the value of RS is greater than one.

The resulting value of RSI indicators ranges between 0 and 1, where 1 means $100 \%$. The main purpose of using RSI indicators is that they may help in deciding whether to buy or sell the position in the market. In practice, it is generally stated that the value of RSI indicators exceeds $30 \%$ upwards, the price has got into oversold and buying is recommended. Conversely, if the value of RSI indicators exceeds $70 \%$ downwards, the prices has moved from overbought and its further decrease is expected; it is thus recommended to sell the position. If the resulting value of RSI indicators ranges around 30-70\% not exceeding any of the limits, it is recommended waiting and monitoring the development. However, experts also recommend not selling buying immediately after the values exceed one of the above limits. If any of the limits is exceeded, the investor should wait until the stock price gets from oversold or overbought and sell or buy afterwards.

After the analysis of moving averages and RSI indicators, the results are processed in the form of a graph with a detailed description of the results and the behaviour of all indications is explained for the investor.

\section{The development process of strategic management of chinese start-up enterprises}

As the first step, value screening of all joint-stock companies was performed. Using the above criteria, a total of six joint-stock companies were found which corresponded to the selected parameters. The first company was a company with the ticker AAPL. This is a ticker of the company Apple Inc., which is based in California and specializes in the production of hardware and software. Their best-known products include e.g. Mac computers, smart phones (IPhone), or tablets (IPad). The second company is a company with a ticker ACN - Accenture plc. The company is based in Ireland and specializes in management consulting, technology services, digital services, and cybernetics. Another company has a ticker CDNS (Cadence Design Systems, Inc.) and is based in San Jose. Its main products include computer software, e.g. chip systems, printed circuit boards or integrated circuits. The ticker of another company is CTXS, it is the company Citrix Systems, Inc. based in Florida, which specializes in software, specifically applications, cloud or virtualization of computers. The fifth company has a ticker TER, Teradyne, Inc. The company is based in Massachusetts and specializes mainly in producing special testing devices. The company is a supplier of many companies with a long tradition, e.g. Samsung or Intel. The last company in the sample is HP Inc. with a ticker HPQ. The company produces computer technology from software through hardware to complete computer systems.

Given that out of the six companies only one of them can be selected for the analysis, the choice is narrowed down using the value of average volume of trades per day. This means that the company with the highest value of the volumes of trade is subject to analysis. In this case, it is the company AAPL - Apple Inc.

The above internet resource provided a dataset of the company Apple Inc. (AAPL) containing data for the period of one year (1 November 2019 - 30 October 2020). The dataset was processed using mathematical calculations described in 
the methodology part of the paper. All additional calculation and graphs were processed using the software Microsoft Excel. As the first step, RSI indicators were calculated using the period of 14 days. The limit of the oversold market is 30 $\%$, while the value of $70 \%$ was selected as a limit for overbought market. In the next step, moving averages were calculated, specifically 50-day, 100-day and 200-day moving averages. All of the values were based on the closing price. As the last step, relevant graphs were created.

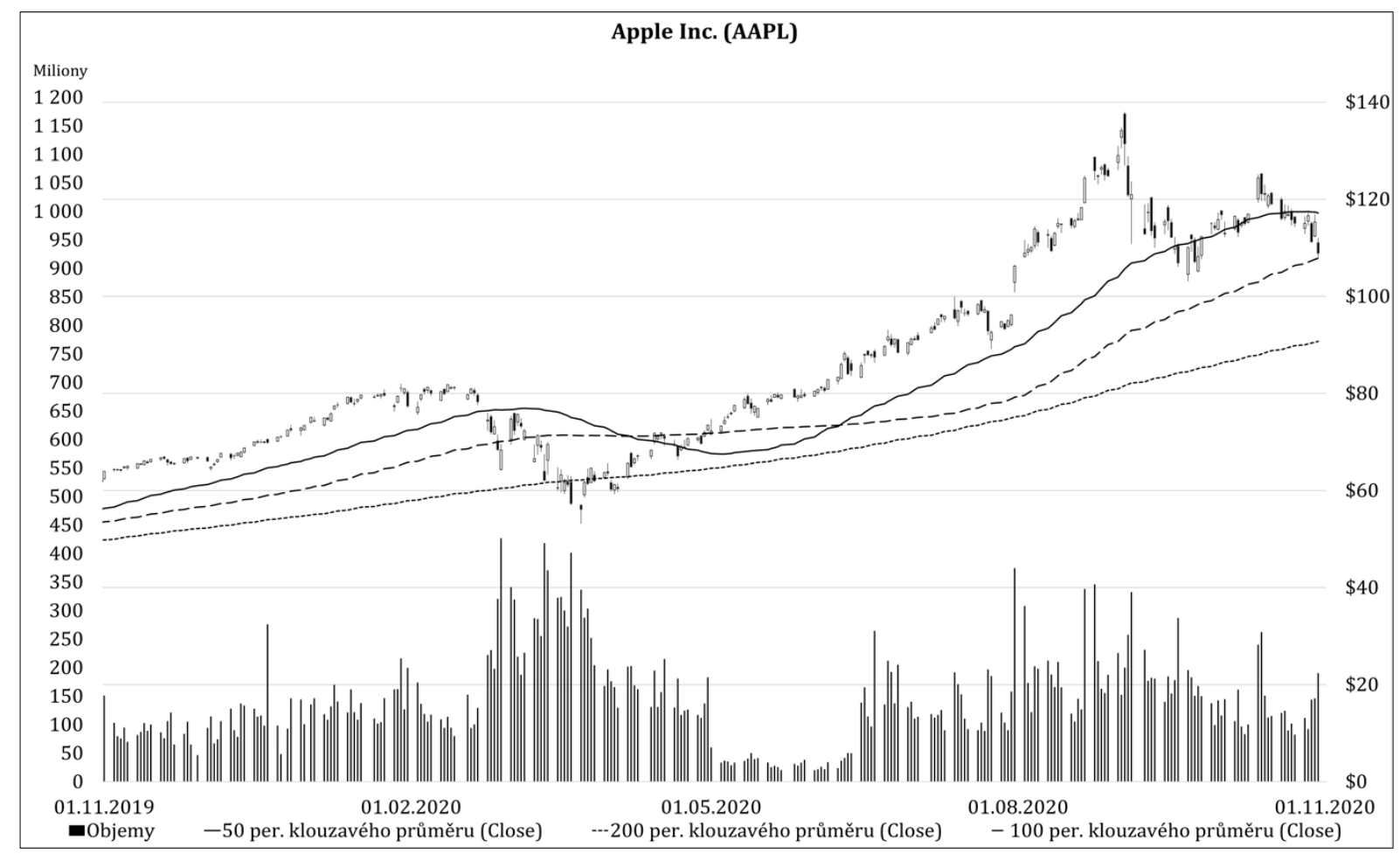

Figure 1. Development of trend, moving average, values of trade volumes

Source: Author.

Legend: objemy - volumes, xper. Klouzavého průměru - x-day moving average.

The above graph describes a trend, moving averages and the volume of trades of Apple Inc. It follows from the graph that from the beginning of the monitored period (1 November 2019), the values showed a stable growth, which is a frequent phenomenon when analysing time series of similar companies. This stable growth continued until the midFebruary 2020, when the coronavirus started, which was naturally reflected in the prices of positions. In the period $2 / 200$ - 3/2020, the prices fell sharply below the initial value from November 2019. However, the crisis has had a relatively manageable impact on technology-oriented companies, which does not apply to companies in other sectors. Apple Inc. as a stable technology company has sufficient financial reserves and such a sharp drop cannot cause its failure. On the contrary, it has happened many times that such a drop helped companies and their stock prices grew much faster in the next period than they would have if there had been no drop. This is also evident from the course of the graph. Approximately from 5/2020, the company's stock prices started to rise steadily at a much faster pace than at the beginning of the year until 9/2020, when the second wave of coronavirus started. This was followed by a sharp drop in price but as 
can be seen from the next development, the company was at least partially prepared for this and the prices started to rise immediately in the next period.

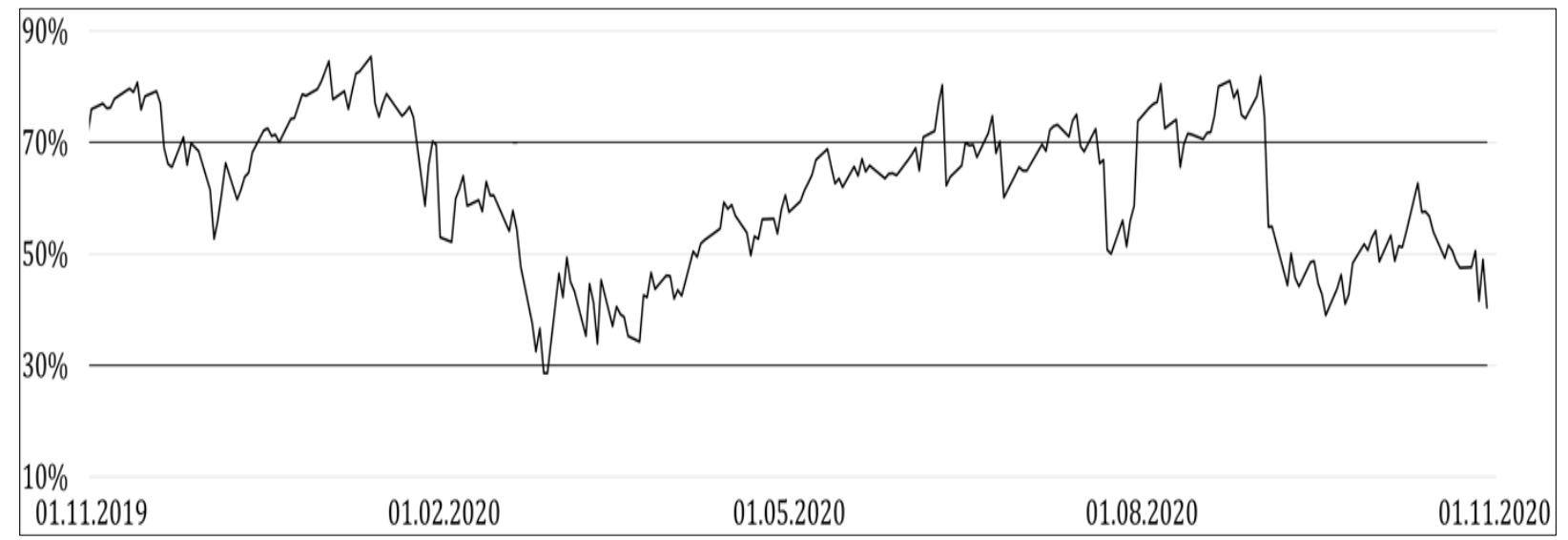

Figure 2. RSI indicators

Source: Author.

The course of the course in the graph describing the RSI indicators is logically very similar as in the previous trend graph. At the beginning of the monitored period, the value of RSI indicators was slightly above $70 \%$ until the end of the year 2019. At the beginning of the year 2020, the price fell below $70 \%$ for a few days but then it sharply increased again up to $80 \%$. This situation lasted until about 2/2020 and then, as shown in the price analysis, with the coronavirus crisis, the prices fell sharply, which was naturally reflected in the development of RSI indicator values, which fell to $30 \%$. In the next period, the company tried to repaired the damages caused by the drop and the values of RSI indicators grew steadily. In 9/2020, with the second wave of the coronavirus crisis, the values of trends and RSI indicators fell suddenly; however, the drop was not as sharp as during the first wave, since the company had had time to prepare at least partially for the situation.

\section{Discussion}

In general, it can be argued that the values of stock prices of almost all companies have fallen since the beginning of the year 2020 due to the coronavirus pandemic. Some experts claim that these have been the lowest values for the last seven years. This drop has caused huge financial problems or even failure of many small enterprises. The company under review, Apple Inc, is not an exception; the coronavirus crisis has affected this company as well. However, a stable company, which Apple Inc undoubtedly is, will be able to recover from the crisis without any major difficulties.

The first part of the results shows the development of Apple Inc stock price and 50-day, 100-day and 200-day moving averages were calculated, which were logically marked as fast, medium, and slow MA. The above graphs indicate that all three types of moving averages did not cross each other until 3/2020 and nearly copied the development of stock prices. This has changed after the aforementioned drop in mid-February 2020, when the stock prices fell sharply. In 4/2020, the fast 50-day MA, which responds most quickly and sensitively to price changes, crossed down the medium 100-day MA. As specified in the methodology chapter of the paper, if fast moving average crosses down the slower MA, it is recommended to sell the position, since in such a case, a drop in prices usually follows. However, this happened only partially in this case, since these technical parameters are focused mainly on a long-term development, in which the fundamental events, such as the coronavirus crisis, are not reflected much. In simple terms, technical parameters work best when there are no events that would have a worldwide effect. Government interventions can also significantly influence technical indicators. In the next period, between June 2020 and July 2020, the situation stabilized and fast MA crossed up the medium MA, which is a signal for a trader to buy positions. Further development shows that in the summer of 2020, when the first wave of the coronavirus crisis was over and government measures were cancelled worldwide and the world was slowly returning back to normal, technical indicators were not influenced by any fundamental events, the recommendation of buying the position would be correct because in the next period, there was a sharp increase in stock prices until September 2020. From the point of view of the moving average, there was no other indicator in the monitored period.

The second part of the results dealt with the analysis of RSI indicators. At the beginning of the monitored period, in November 2019, their values were slightly above $70 \%$, which did not produce any sign for buying or selling; according to the experts, the ideal reaction is to wait for further development. The first clear sign appeared at the beginning of 2020 , when the values of RSI indicators were below $70 \%$ and suddenly sharply crossed the limit of $70 \%$. In such a case, the ideal reaction is to sell the position in the market; according to the next development, this is the right solution, as if the trader had sold the position at the beginning of 2020, they would avoid the sharp drop in stock prices between $2 / 2020$ and 3/2020. In mid-March 2020, the values of RSI indicators were slightly below $30 \%$ and rose again. This means that they crossed up the limit of $30 \%$; in such a case, the ideal reaction is to buy in bulk. If a trader reacted to this indicator and 
made a purchase in March 2020, this would bring them a high profit, since in the next period, stock prices increased sharply. In 6/2020, the values of RSI indictors crossed up the limit of $70 \%$ and fluctuated around this value for some time. In 8/2020, they fell down sharply, crossing down the limit of $70 \%$. This indicator recommends giving up the position. If a trader did this, it would again bring them profit, since a month later, the second wave of the coronavirus started and stock prices fell sharply again.

In November 2020, neither moving averages nor RSI indicators produced any signals that would recommend selling or buying positions. The ideal reaction thus appears to be not to change the share portfolio and hold the position, or do not buy and wait for further development and other indicators.

\subsection{Evaluation of hypotheses}

According to the first hypothesis, the determined criteria of value screening will find a maximum of 4 companies. This hypothesis can be rejected because the value screening found a total of 6 companies, out of which the one with the most traded stocks was selected. In this case, it was the company Apple Inc.

The second hypothesis was that the technical analysis indicators recommend sell or buy immediately after the beginning of the monitored period, i.e. around November 2019. The hypothesis was also rejected, since the first indicator emerged around February 2020.

The third hypothesis was formulated as follows: RSI indicators will recommend sell or buy, which will prove to be potentially correct in the next period. RSI indicators recommended specifically two positions. The first of them appeared at the beginning of the year, when the ideal reaction seemed to be selling the position. This turned out to be crucial in the future, since during the first wave of the coronavirus pandemic, a sharp drop in stock prices was recorded. The second indicator emerged in mid-March 2020, when it was recommended buying the positions. As further development showed, this decision would be right since in the next period, stock prices grew. This hypothesis can thus be confirmed.

\section{Conclusion}

The objective of the paper was to use determined criteria of value screening to select a relevant company for the analysis of its time series using selected methods of technical analysis.

In the introduction, the issue of stock time series was generally defined and general information on its evaluation was provided. Literary research presented the views of other authors to the issue of stock series and technical analysis. In the methodology part, the most common methods used for the evaluation of stock series were described, specifically moving averages and RSI indicators. Moreover, value screening was specified and its parameters were set. The Results part describes the graphs created and explains the results presented. In the chapter dealing with the discussion of the results, specific indicators are described, which emerged in the analysis of the time series and recommendations for traders are made. The conclusion part summarizes the whole structure and process.

\section{References}

1. P. Růčková. Finanční analýza. Praha: Grada Publishing a. s. ISBN 987-80-271-2028-4 (2019)

2. B. Graham. Inteligentní investor. Praha: Grada Publishing a. s. ISBN 978-80-247-1792-0 (2007)

3. D. Gladiš. Akciové investice. Praha: Grada Publishing a. s. ISBN 978-80-247-5375-1 (2015)

4. D. Gladiš. Naučte se investovat. Praha: Grada Publishing a. s. ISBN 80-247-1205-9 (2005)

5. Rejnuš, O., 2014. Finančni trhy. Praha: Grada Publishing a. s. ISBN 987-80-247-3671-6 (2014)

6. P. Syrový. Investováni pro začátečniky. Praha: Grada Publishing a. s. ISBN 978-80-271-0092-7 (2016)

7. D. Štýbr. Začináme investovat a obchodovat na kapitálových trzích. Praha: Grada Publishing a. s. ISBN 987-80247-3648-8 (2011)

8. P. Podhajský, T. Nesnídal. Obchodování na komoditních trzích: průvodce spekulanta. Praha: Grada Publishing a. s. ISBN 80-247-1851-0 (2006)

9. O. Hartman. Začínáme na burze. Praha: Grada Publishing a. s. ISBN 987-80-265-0780-2 (2018)

10. J. Václavíček. E-Milionářr. Praha: Grada Publishing a. s. ISBN 987-80-7252-220-0 (2008)

11. A. Picasso, S. Merello, Y. Ma, L. Oneto, E Cambria. Technical analysis and sentiment embeddings for market trend prediction. Expert Systems with Applications. 135, 60-70 doi:10.1016/j.eswa.2019.06.014 (2019)

12. D. P. Gandhmal, K. Kumar. Systematic analysis and review of stock market prediction techniques. Computer Science Review. 34 doi:10.1016/j.cosrev.2019.08.001 (2019) 
13. D. Shah, H. Isah, F. Zulkernine, F., 2019. Stock market analysis: A review and taxonomy of prediction techniques. International Journal of Financial Studies. 7(2) doi:10.3390/ijfs7020026 (2019)

14. B. Weng, L. Lu, X. Wang, F. M. Megahed, W. Martinez. Predicting short-term stock prices using ensemble methods and online data sources. Expert Systems with Applications. 112, 258-273 doi:10.1016/j.eswa.2018.06.016 (2018)

15. G. Kumar, S. Jain, U. P. Singh. Stock Market Forecasting Using Computational Intelligence: A Survey. Archives of Computational Methods in Engineering. 28(6) doi:10.1007/s11831-020-09413-5 (2020)

16. W. Wang, L. Weizi, Z. Ning, L. Kecheng. Portfolio formation with preselection using deep learning from long-term financial data. Expert Systems with Applications. 143 doi:10.1016/j.eswa.2019.113042 (2019)

17. K. Li, P. Mohanram. Fundamental Analysis: Combining the Search for Quality with the Search for Value. Contemporary Accounting Research. 36, 1263-1298 doi:10.1111/1911-3846.12466 (2019)

18. K. S. K. Lam, L. Dong, B. Yu. Value premium and technical analysis: Evidence from the China stock market. Economies. 7(3) doi:10.3390/economies7030092 (2019)

19. O. Bustos, A. Pomares-Quimbaya. Stock market movement forecast: A Systematic review. Expert Systems with Applications. 156 doi:10.1016/j.eswa.2020.113464 (2020)

20. J.-N. Wang, H.-CH. Liu, J. Du, Y.-T. Hsu. Economic benefits of technical analysis in portfolio management: Evidence from global stock markets. International Journal of Finance and Economics. 24(2), 890-902 doi:10.1002/ijfe.1697 (2019) 